\title{
Use of khat and posttraumatic stress disorder as risk factors for psychotic symptoms: A study of Somali combatants
}

\author{
Michael Odenwald ${ }^{\mathrm{a}, *}$, Harald Hinkel ${ }^{\mathrm{b}}$, Elisabeth Schauer ${ }^{\mathrm{a}, \mathrm{c}}$, Maggie Schauer ${ }^{\mathrm{a}}$, Thomas Elbert ${ }^{\mathrm{a}}$, \\ Frank Neuner ${ }^{\mathrm{a}}$, Brigitte Rockstroh ${ }^{\mathrm{a}}$ \\ ${ }^{a}$ University of Konstanz, Konstanz, D-78476, Germany \\ ${ }^{\mathrm{b}}$ The World Bank, The World Bank Multi-Country Demobilization and Reintegration Program of the Greater Great Lakes Region, Goma, Democratic Republic of Congo \\ ${ }^{\mathrm{c}}$ Vivo international, Ancona, Italy
}

\author{
Keywords: \\ Somalia \\ Khat \\ Psychosis \\ Ex-combatants \\ Posttraumatic stress disorder (PTSD) \\ Combatants \\ Functional Drug Use \\ Cathinone \\ Mental health \\ Armed Conflict \\ Disarmament \\ Demobilization \& Reintegration (DDR)
}

\begin{abstract}
A B S T R A C T
The chewing of the khat leaves, which contain the amphetamine-like cathinone, is a traditional habit in Somalia. Our objective was to explore the effects of khat use and Posttraumatic Stress Disorder (PTSD) on paranoid symptoms and to test a potential causal chain. We report on a cross-sectional study in Somalia that was conducted in 2003. Trained local staff interviewed 8723 personnel of armed groups in seven regional convenience samples. Of them, 8124 were included in the analysis. We assessed current khat use, PTSD symptoms, functional drug use and paranoid ideation using items from the Composite International Diagnostic Interview (CIDI) and the Somali version of the Posttraumatic Stress Diagnostic Scale (PDS). Applying the causal steps approach, in a series of logistic regression models, we used PTSD as independent and paranoia as outcome variable; the quantity of khat use was defined as mediator variable and functional drug use as moderator. The results showed that respondents with PTSD used khat more frequently. Khat chewers with PTSD reported a higher intake compared to khat chewers without PTSD. Among excessive khat chewers with PTSD, paranoia was most frequent. The greatest amount of khat use was among respondents with PTSD who indicated that they found drugs help them to forget war experiences. The proposed mediated moderation model was supported by the data, i.e. besides the direct effects of PTSD and functional drug use on paranoia, the amount of khat use appeared to be a mechanism, by which paranoia is caused. We conclude that in our data we have uncovered a relationship between khat, PTSD and paranoia. Khat is functionally used by respondents with PTSD. Findings support a dose effect: the more khat consumption and when a respondent has PTSD, the higher the odds for paranoid ideation. However, the proposed causal chain needs to be confirmed in longitudinal studies. Demobilization and reintegration programs in Somalia need to be prepared to deal with complex psychological problems.
\end{abstract}

\section{Introduction}

In Somalia, where internal conflict has lasted for more than 20 years now, and in neighboring countries chewing khat leaves is a traditional practice that is believed to go back to ancient times (Krikorian, 1983). During the recent decades, the former niche product khat, which had traditionally only been consumed by certain regional, ethnic and religious groups, has had a remarkable boom and its production is now the backbone of several national economies, for example Yemen or Ethiopia (Anderson, Beckerleg,

\footnotetext{
* Corresponding author. Department of Psychology, University of Konstanz, FACH D25, 78457 Konstanz, Germany. Tel.: +49 7531884041.

E-mail address: michael.odenwald@uni-konstanz.de (M. Odenwald).
}

Hailu, \& Klein, 2007). In 1996 it was estimated that about 6 million individual portions are consumed each day on a worldwide scale (Kalix, 1996). The main psycho-active component within these leaves is cathinone, ( $\mathrm{S}(-)$ alpha-aminopropiophenone (Szendrei, 1980). Biomedical research highlights that cathinone resembles amphetamine in chemical structure and similarly affects the central and peripheral nervous system as well as behavior (Kalix, 1996) while the social sciences focus on the cultural functions (Anderson et al., 2007). Here, we present a study with active combatants in Somalia, which addresses the functions and consequences of khat use in relation to war-trauma. We aimed at applying biomedical concepts as useful tools in the Somali context as suggested by Zarowsky and Pedersen (2000), taking PTSD into the context of social suffering and with a special attention for local patterns of distress and coping (Kienzler, 2008). 
Substance abuse among active combatants to cope with warrelated stress can be considered a global phenomenon (WHO, 2008). In the USA, substance-related problems as well as PTSD have been identified as common problems among ex-combatants (Kulka et al., 1990) and are seen as risk factors for different aspects of their readjustment to civilian life (Savoca \& Rosenheck, 2000). Functional use of drugs, especially to control or reduce negative mood states is common among substance users and predict the amount of substances used (Boys \& Marsden, 2003). Current knowledge supports the self-medication hypothesis for central nervous system (CNS) depressants like alcohol, i.e. their use to suppress PTSD symptoms (Jacobsen, Southwick, \& Kosten, 2001). Only a few studies have ever investigated the functions of stimulant use in PTSD. They show that individuals with PTSD use CNS-stimulants and that there is, in general, a functional relationship between stimulant use and PTSD (Coffey, Schumacher, Brady, \& Cotton, 2007). Subjective effects of CNS-stimulants differ in relation to the PTSD symptom clusters (intrusion, avoidance, hyperarousal). The intrusive and hyperarousal symptoms become worse when stimulants are used in moments when situational cues activate traumatic memories (Coffey et al., 2002). Other studies report a pleasant effect on the avoidance symptom cluster, numbing and co-morbid depression (Brady, Dansky, Sonne, \& Saladin, 1998; Daly, 2000).

In the Somali tradition, the social act of khat chewing has an important function for coping with the experience of violence, especially as the khat session becomes a source of social support (Zarowsky, 2000). Khat is also used for coping with other kind of stressors. Rousseau, Said, Gagne, and Bibeau (1998) studied the unfulfilled wishes among young Somalis to leave their country in order to pursue an academic or professional career abroad. They describe how in this extended period of transition excessive khat use is a frequent response to cope with insecurity and hopelessness and how it contributes to the development of mental illness. Studies among Somali refugees living in western countries report khat use in order to cope with the psychological problems associated with staying in a foreign and hostile environment or with past traumatic experiences (Fangen, 2006; Nabuzoka \& Badhadhe, 2000).

Amphetamine-type drugs are an especially dangerous type of substance to be functionally used to cope with stress or PTSD. They have been shown to induce psychotic symptoms in experimental settings in humans (Bell, 1973) and animals (Kalivas \& Stewart, 1991) and they exacerbate psychotic states in psychiatric patients (Angrist, Rotrosen, \& Gershon, 1980). These drugs induce lasting changes in the brain and in behavior (Baicy \& London, 2007). Amphetamine-type stimulants and stress lead to cross-sensitization in animal models for psychosis (Kalivas \& Stewart, 1991). Crosssensitization of amphetamine use and stress to the re-emergence of psychotic symptoms has recently been identified among humans in a highly controlled prison environment (Yui et al., 2001). Also khatinduced psychotic states have been described in over 20 case reports (Warfa et al., 2007) and, recently, community-based studies showed that khat use is associated with severe psychiatric problems (Bhui et al., 2006). Furthermore, khat use has been identified by caretakers as one of the main cause of relapse among psychotic patients in Ethiopia (Bimerew, Sonn, \& Korlenbout, 2007). While moderate khat chewing may elicit psychotic symptoms only in especially vulnerable individuals, excessive and prolonged use seems to be noxious particularly when started early in life (Advisory Council on the Misuse of Drugs, 2005). Excessive abuse has become a common phenomenon among combatants in Somalia during the course of the ongoing conflict (Odenwald, Hinkel, et al., 2007). In a cross-sectional study in Hargeisa, Somaliland, $16 \%$ of former combatants were severely impaired in their everyday functioning due to psychiatric problems, consisting mostly of psychotic disorders and associated excessive khat abuse (Odenwald et al., 2005). This study revealed a significant relationship between the amount of khat use and the number of traumatic events experienced. In another study with 64 Somali ex-combatants, we found a prolonged khat use among respondents with PTSD and that 8 of 14 individuals with PTSD also had co-morbid psychotic features (Odenwald, Lingenfelder, et al., 2007). In this context, it is important to acknowledge that a substantial number of ex-combatants with PTSD have secondary co-morbid psychotic symptoms, which mostly consist of auditory hallucinations, paranoid and referential delusions and which are related to more severe PTSD symptoms and to more behavioral problems (Braakman, Kortmann, \& van den Brink, 2009). Recently, early trauma exposure was identified as a risk factor for the development of schizophrenia and PTSD was linked to the development of psychosis on different levels (Seedat, Stein, Oosthuizen, Emsley, \& Stein, 2003). Studies on the effects of stimulant use on co-morbid psychotic features among individuals with PTSD are lacking.

In non-western (post-)conflict zones, little is currently known about these complex problems related to PTSD, functional drug use and related complications (Mogapi, 2004). This lack of information hinders the efforts made by disarmament, demobilization and reintegration (DDR) programs in many post-conflict countries, i.e. to develop adequate medical and psycho-social tools that respect the local patterns of suffering and coping.

Through this study we wanted to increase the knowledge of psychological problems in (post-)conflict Somalia that appear to be related to reintegration failure of ex-combatants in order to improve future DDR programs. We especially aimed at getting a more complete picture about a complex phenomenon, disentangling the effects of khat use and PTSD on psychotic symptoms. The adverse effects of khat use have recently been questioned and the hypothesis has been introduced that all psychopathology in the reported community-based studies can be explained by stress exposure alone (Pennings, Opperhuizen, \& van Amsterdam, 2008). We used a large cross-sectional data set that had not been analyzed with respect to mental health aspects other than drug use (Odenwald, Hinkel, et al., 2007).

Our hypotheses were that both factors, PTSD and khat use would explain part of the variation of psychotic symptoms. Based on the reviewed literature, we conceptualize PTSD as an independent variable, paranoia as an outcome, and khat use as a mediating variable. A mediating variable represents a mechanism, by which the independent variable exerts its effect on the dependent variable. Furthermore, we assumed that the trait-like characteristic functional drug use plays a moderating role, i.e. by independently influencing the motivation to use khat. More specifically, a person with a high posttraumatic symptom level who experiences the effects of khat or other drugs as helpful to cope with traumatic memories or other posttraumatic symptoms will probably use more of it compared to another person with the same symptom level but who doesn't experience this drug effect. In Fig. 1, we graphically display the hypotheses. In our study, we took typical cultural phenomena in Somalia into consideration, including the common belief in spirits or witchcraft, which should not necessarily be seen as signs of psychopathology (Ndetei, 1988). In Somalia, the beliefs in ghosts, spells or jinx must be considered non-psychiatric phenomena, as well as some forms of spirit possession (e.g. "Zar").

\section{Methods}

\section{Design, sampling and participants}

Our data originate from a study among personnel of armed groups, which was conducted as a small part of a preparatory 

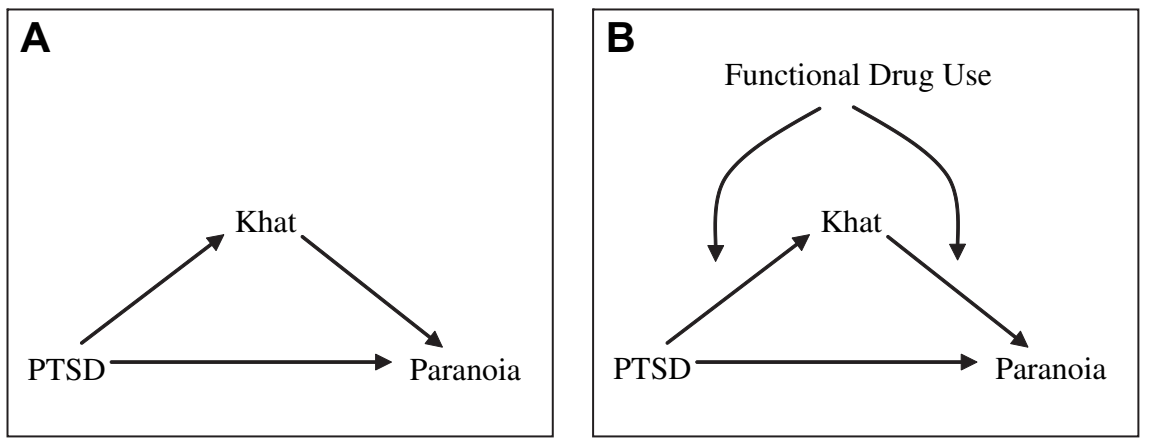

Fig. 1. Graphical depicted hypotheses. A) Simple mediation: Additionally to the direct effect that PTSD exerts on paranoia, khat is responsible for an indirect effect, i.e. khat is a mediating variable between PTSD and paranoia. B) Mediated moderation: the direct effect of PTSD on paranoia is moderated by the relatively stable individual characteristic Functional Drug Use; the quantity of khat use is the mechanism that mediates this moderating effect.

project for an international DDR program. In 2003, international organizations estimated that the total number of men under arms lies between 70,000 and 80,000 in Somalia (Hinkel, 2004). Of them 17,600 were in Somaliland, 6500 in Puntland (Smith, 2002), and approximately 17,000 in Mogadishu (Hinkel, 2004). Given that the country remains in armed conflict, it was not possible to apply random sampling methods. Thus, we drew seven large convenience samples in seven parts of the country. The use of convenience samples does not allow for the estimation of biases, and thus prevalence estimates must be interpreted with caution. However, in this study we assumed that selection biases would still allow us to study the associations of variables.

The seven parts of Somalia with the highest estimated military staff density were selected for interviews, including major population centers and rural areas: In the North of Somalia, we included Somaliland and Puntland; in central Somalia, Hiran; and in southern Somalia Bay/Bakol, Mogadishu and Kismayo. Mogadishu was divided in two samples according to the "green line," which divided the town between main factions at the time of the interviews. Mogadishu South included the Lower Shabelle region with the town of Merka. For a more detailed description of sampling methods, please refer to Odenwald, Hinkel, et al. (2007). In every region, we aimed to assess a minimum of 600 respondents, including as many factions and armed groups as possible, with the request that a minimum of one unit within the overall structure be completely assessed. We had no access to basic information concerning the units (e.g. actual size of units) chosen for this assessment.

Interviews were conducted between August and December 2003. The interviewers went directly into a compound used by the respective militia or units to conduct the individual interviews in a place that provided as much privacy as possible, e.g. in a separate room.

In total, 8723 militiamen and security staff were interviewed; 587 of them were excluded from the analysis because they denied their consent after being informed about the purpose of the study (empty sheet returned) or during the interview (6.7\%) and 12 because their interviewers did not fulfill minimal standards (a minimum of ten interviews per interviewer was required), resulting in 8124 (93.1\%) interviews entering statistical analysis. We reached about $11 \%$ of the total estimated number of armed personnel in all Somalia. Of them, 4070 belonged to regional authorities and 2290 to warlord factions, 1090 were members of freelance and clan-based militia, 481 of sharia court militias, and 78 members of business militias.

Respondents' socio-demographic characteristics are reported in Table 1. In our sample, we had 882 women (10.9\%) and 7242 men (89.1\%). 758 of the women were from northern Somalia (85.9\%). On average they were $37.3 \pm 12.6$ years of age and $67.5 \%$ were married.
Less than half of them had completed primary education and even less had received any vocational training. Only about two thirds reported combat experience.

\section{Instrument}

Questions and their answers were developed in English by an interdisciplinary team consisting of Somali and international experts with a particular focus on cultural adequacy, and then translated and independently back-translated by professional translators. In case the back-translation revealed a mismatch in semantic content, the item was revised in this group and then once again independently back-translated.

\section{PTSD}

We assessed symptoms of PTSD using items of a modified version of the Posttraumatic Stress Diagnostic Scale (PDS; Foa, 1995). The PDS is a widely used self-report instrument for the assessment of PTSD according to the DSM-IV with good psychometric properties and validity, i.e. Cronbach's Alpha of 0.92, restretest reliability of 0.83 , and a kappa of 0.74 compared to the SCIDPTSD module (Foa, Cashman, Jaycox, \& Perry, 1997). In a study with

Table 1

Socio-demographic variables of respondents. Point estimates are uncorrected means and standard deviations (in brackets) or proportions and 99\% CIs. Bracket in heading is total $N$.

\begin{tabular}{|c|c|}
\hline Variable & $\begin{array}{l}\text { Mean (SD) or proportion; } \\
\text { CI 99\% }(8124)\end{array}$ \\
\hline$\overline{\text { Age }}$ & $37.3(12.6) ; 36.9-37.7$ \\
\hline Proportion of male respondents & $89.1 \% ; 88.2-90.0$ \\
\hline Proportion of married respondents & $67.5 \% ; 66.2-68.8$ \\
\hline Number of dependants & $6.2(5.7) ; 6.0-6.4$ \\
\hline $\begin{array}{l}\text { Proportion of respondents } \\
\text { with at least completed } \\
\text { primary education }\end{array}$ & $44.4 \% ; 43.0-45.8$ \\
\hline $\begin{array}{l}\text { Proportion of respondents } \\
\text { with any vocational training }\end{array}$ & $23.4 \% ; 22.2-24.6$ \\
\hline $\begin{array}{l}\text { Proportion of respondents } \\
\text { with combat experience }\end{array}$ & $65.1 \% ; 63.7-66.5$ \\
\hline Age of first combat ${ }^{\mathrm{a}}$ & 22.9 (8.7); 22.6-23.2 \\
\hline Years in combat ${ }^{\mathrm{a}}$ & $1.9(2.6) ; 1.8-2.0$ \\
\hline $\begin{array}{l}\text { Proportion of respondents } \\
\text { with khat use in the } \\
\text { previous week }\end{array}$ & $36.4 \% ; 35.0-37.8$ \\
\hline $\begin{array}{l}\text { Amount of khat use in } \\
\text { previous week }^{\mathrm{b}}\end{array}$ & $9.8(11.4) ; 9.3-10.3$ \\
\hline
\end{tabular}


64 Somali ex-combatants (Odenwald, Lingenfelder, et al., 2007), the Somali version of the PDS achieved a Cronbach's Alpha of 0.86 and referenced to the Composite International Diagnostic Interview PTSD module (World Health Organization, 1997) a sensitivity of 0.90 and specificity of $0.90(\kappa=0.69, p<.001)$. Based on this preparatory work, we selected five symptom items of the Somali PDS, in order to screen for PTSD: unwanted memories of the traumatic event, avoidance of talking about or thinking about the traumatic event, the sense of a shattered future, sleeping problems and exaggerated startle. Additionally we asked one question to assess for PTSD criterion A, as specified by DSM-IV (exposure to lifethreatening events and individual reaction of intense fear, helplessness or horror): "Did you ever feel helpless or horrified when you were in a situation in which your life was in danger or when you directly observed that somebody else's life was in danger?" All PTSD items were coded in a yes-no format related to the past four weeks. The scale made of the five symptom items demonstrated good internal consistency (Cronbach's Alpha $=0.78$ ). Screening PTSD was coded when all five symptom items and the event item were answered positively. Against the CIDI diagnosis of PTSD, screening PTSD as defined above, had a specificity of 0.96 and a sensitivity of 0.55 ; the inter-rater reliability was above chance (kappa $=0.57, p<.001$ ). Assuming a true PTSD prevalence of approximately $20 \%$ in this population (Odenwald, Lingenfelder, et al., 2007), this means that among 100 subjects, 3 out of 80 nonPTSD cases would be not correctly classified and 9 out 20 PTSD cases would not be detected - in sum, 78.6\% of screening PTSD cases have PTSD. This is a relatively conservative detection procedure, which underestimates the true PTSD prevalence but minimizes the inclusion of non-PTSD cases.

Khat intake was assessed for by asking about the individual's khat intake during the previous week: First we asked whether the interviewee would use the "Herari"-type khat from Ethiopia or the "Miraa"-like variety from Kenya. If a positive answer was given, we asked to estimate the number of 'bundles' (traded units) consumed in the last week. We trained the interviewers to assist respondents to estimate their khat use in relation to the bundles that they normally consumed, even when they had consumed single twigs or leftovers from others ("How many bundles of the type of khat you normally consume would this be?"). This method proved to be reliable and valid in our previous studies, e.g. a high correspondence to other methods to quantify khat use and significant correlations to measures of psychopathology (Odenwald, Lingenfelder, et al., 2007; Odenwald et al., 2005).

\section{Functional drug use}

In order to explore whether substance use serves in a functional way, i.e. to reduce suffering related to PTSD symptoms, we asked the following question: "Does khat or other drug use help you to forget your stressful war experiences?" The answer was coded in a yes-no format.

\section{Psychotic symptoms}

Paranoid delusions are the most frequently observed psychotic symptoms induced by excessive khat use (Odenwald, 2007) and are a common symptom of PTSD with co-morbid psychotic features (Braakman et al., 2009). They were assessed by item G4 of the Composite International Diagnostic Interview (CIDI, World Health Organization, 1997); "Do you think that someone is plotting against you or trying to hurt or poison you?"). Interviewers were trained to first read the item. In case the interviewee gave a positive answer, the interviewer asked him to explain why he thinks so. The interviewers were instructed to rate whether the respondent's answer referred to a real danger, to a non-psychotic expression of a culturetypical belief (Ndetei, 1988) or to a clinical symptom. Only in the latter case would the item be counted as positive (yes-no format). This single item coding of psychiatric symptoms is frequently used to assess psychiatric symptoms (Bhui et al., 2003).

\section{Interviewers, training and supervision}

Interviewers were staff of local NGOs with interviewing experience in mental health or psycho-social assessments $(N=38)$. Prior to data collection, a 14-day training course was conducted. The training contained introduction of clinical concepts and research design, role-plays and field exercises. Contact with interviewers was maintained throughout the assessment phase by satellite phones, radio and field visits by one Somali team member.

\section{Approval and ethics}

The Cease Fire, Disarmament, and Demobilization Committee (Committee 2) of the Somali Peace and Reconciliation Conference in Mbaghati, Nairobi, the National Demobilization Commission in Hargeisa, the Somalia Unit of the European Commission (Nairobi), the German Agency for Technical Cooperation, International Services (Nairobi) approved the assessment. All participants were informed before the interview about the purpose and method of the interview, confidentiality and about the possibility to discontinue the interview at any time without negative consequences. All participants were assured that a refusal to participate would not be reported to superiors. Interviews were only conducted after respondents had given verbal consent. We accepted oral consent because of the high rate of illiteracy.

\section{Statistical analysis}

Data were analyzed with SPSS 11.0 for Macintosh. We report uncorrected proportions in percents and for continuous variables, uncorrected means and standard deviations $(\mathrm{M} \pm \mathrm{SD})$. We calculated $99 \%$ confidence intervals (CIs) for all point estimates. Because of interpretation problems of data from convenience samples, we wanted to focus on the clearest differences and opted for Alpha 0.01 . Group differences were analyzed using one-way ANOVA or $t-$ test (Kruskal Wallis or Wilcoxon in case the prerequisites were not met) and $C^{2} i^{2}$ test (Fisher's exact test in case prerequisites were not met). We opted against post-hoc tests and relied on $99 \% \mathrm{CI}$ for further group differences. Phi was used to express the correlation between two dichotomous variables. In order to explore the effects of functional drug use and PTSD on the quantity of khat consumption, we used univariate ANOVA. Here we report 99\% CI based on the estimation of standard errors when keeping the other factor constant. We tested a potential causal network of the above reported variables using the moderator-mediator approach (Baron \& Kenny, 1986) and its further development (Muller, Judd, \& Yzerbyt, 2005) relying on binary logistic regression models (MacKinnon \& Dwyer, 1993). In six logistic regression models predictors were subsequently entered in two blocks into the equation regardless of their prediction power (enter). Control variables in block 1 were entered always into models: age (continuous), gender (reference: female), primary education (reference: primary education not completed) and marital status (reference: not married/divorced). Variables of interest and their interactions were entered in block 2 according to the specific model: PTSD (reference: no PTSD), functional drug use (reference: no) and a dichotomized variable of the quantity of khat bundles chewed in the week before the interview (khat quantity; reference: lower khat use). The variable was created using the median of the khat bundles distribution among respondents with PTSD as cut-off. For all three variables of interest we used a binary coding in order to minimize complexity. As suggested by Muller et al. (2005), we don't apply statistical test for the 
complex interaction of mediation and moderation. Model fit was tested using the likelihood ratio test.

\section{Results}

\section{Parameter values}

\section{Khat use}

Khat chewing during the last week was reported by 2955 participants (36.4\%, 99\% CI 35.0\%-37.8\%). Khat chewing was reported more frequently in the South of the country $(26.2 \%, 99 \% \mathrm{Cl}$ $24.4-27.6$ vs. $50.7 \%, 99 \%$ CI $47.8-52.2 ; p<.001$ ). Only 12 women $(1.4 \%, 99 \%$ CI $0.3-2.3)$ in contrast to 2943 men $(40.6 \%, 99 \%$ CI $38.5-$ 41.5) reported khat use in the previous week $(p<.001)$, three of them in northern Somalia. On average, participants consumed $3.6 \pm 8.3$ bundles of khat in the previous week $(99 \%$ CI 3.4-3.8). The 12 khat chewing women, had consumed the same amount of khat as male chewers in the week before the interview (female vs. male: $12.8 \pm 19.1,99 \%$ CI $0.0-27.0$ vs. $9.7 \pm 11.3,99 \%$ CI 9.2-10.2; $p=.907)$.

\section{PTSD}

PTSD was found in 456 subjects $(5.6 \%, 99 \%$ CI 4.9-6.3); in the North of the country, PTSD was seldomly found $(2.1 \%, 99 \%$ CI $1.5-2.5$ vs. $10.6 \%$, 99\% CI $9.5-12.5 ; p<.001$ ). Only 16 females were found with PTSD (female vs. male: $1.8 \%$, $99 \%$ CI $0.7-3.0$ vs. $6.1 \%, 99 \% \mathrm{CI}$ 5.3-6.7; $p<.001)$. Of them, 4 were from the North. Khat chewing was more frequent among subjects with PTSD (66.2\%; 99\% CI 60.571.9 vs. $34.6 \%, 99 \%$ CI $28.8-40.4 ; p<.001$ ), and khat chewers with PTSD consumed higher quantities than khat chewers without PTSD (18.8 \pm 16.3 bundles, $99 \%$ Cl 16.8-20.8 vs. $8.7 \pm, 10.2$, 99\% CI 8.4-9.0; $p<0.001)$.

\section{Paranoid ideation}

Paranoid ideation was found in 396 respondents $(4.9 \%, 99 \% \mathrm{Cl}$ 4.3-5.5). In the North, we found paranoid ideation more seldomly (1.8\%, 99\% CI $1.3-2.3$ vs. $9.2 \%, 99 \%$ CI $7.8-10.4 ; p<.001)$. Only 12 female respondents reported paranoid ideation, less than among males $(1.4 \%, 99 \%$ CI $0.3-2.3$ vs. $5.3 \%, 99 \%$ CI $4.6-6.0 ; p<.001)$. Among respondents with PTSD, this rate was $26.1 \%$ (99\% CI $20.8-$ 31.4), among those without PTSD it was 3.6\% (99\% CI 3.0-4.2; $p<.001$ ). Among khat chewers, this rate was with $8.9 \%$ (99\% CI 7.5$10.3)$ higher than among non-khat chewers $(2.6 \%, 99 \%$ CI 2.0-3.2; $p<.001)$.

\section{Functional drug use}

In total, 1577 subjects (19.4\%, 99\% CI 17.9-20.1) affirmed that khat or other drug use would help to forget their stressful war experiences. This proportion was smaller in the North of the country (5.3\%, 99\% CI 4.5-6.1 vs. 39.3\%, 99\% CI 36.8-41.1; $p<.001$ ). Of them, 18 were female (female vs. male: $2.0 \%, 99 \%$ CI $0.8-3.2$ vs. $21.5 \%, 99 \%$ CI $19.8-22.2 ; p<.001)$. Among all respondents, subjects with PTSD (456) more frequently indicated that khat or drugs help them to forget stressful war experiences compared to subjects without PTSD (7667; 77.6\%, 99\% CI 91.9-82.1 vs. 16.0\%, 99\% CI 13.9$16.1 ; p<.001)$. This was also the case if we restricted our analysis to only those respondents with lifetime combat exposure (5286; $79.7 \%$, $99 \%$ CI $73.5-84.5$ vs. $22.3 \%$, $99 \%$ CI $20.5-23.5 ; p<.001$ ), to current khat users $(2.955 ; 95.3 \%, 99 \%$ CI $91.8-98.2$ vs. $40.5 \%, 99 \% \mathrm{CI}$ $37.6-42.5 ; p<.001)$ or to current khat users with lifetime combat exposure $(2261 ; 96.0 \%$, 99\% CI $92.8-99.2$ vs. $48.6 \%$, 99\% CI $45.1-$ $50.8 ; p<.001)$.
In Table 2, we report the probabilities to be screened positive for paranoia among groups of respondents relative to functional drug use and PTSD. At both levels of functional drug use PTSD is associated with an increased probability for paranoia $(p<.001)$. Comparing veterans with PTSD who found khat or drugs helpful with those who did not, we found that the former report more psychotic symptoms $(p=.007)$.

The comparison of all those respondents who find khat or drugs helpful to forget stressful war experiences with those who don't regardless of PTSD, reveals that among the former $82.7 \%$ (99\% CI 79.5-84.5) report that they've experienced upsetting memories related to past war events in the last 4 weeks compared to $29.8 \%$ (99\% CI 27.4-30.6) of the latter $(P h i=.44 ; p<.001)$.

\section{Testing the hypotheses}

Are respondents with PTSD functionally using khat? We compared the amount of khat use between groups with and without PTSD and with and without functional drug use. Using univariate ANOVA we found main effects of PTSD $(F=37.199$; df $1 ; p<.001)$ and functional drug use $(F=693.108$; df $1 ; p<.001)$ and an interaction effect of both variables $(F=60.493$; df $1 ; p<.001)$ on self-reported khat use (Total Adjusted $R^{2} .214$ ). In Fig. 2, we graphically display this interaction effect. Subjects who indicated that khat helps them to forget war experiences used significantly more khat in the previous week when they also had PTSD compared to the ones without PTSD $(15.7 \pm 11.1$ bundles, $99 \%$ CI $14.7-16.7$ vs. $9.7 \pm 11.9$, 99\% CI 9.2-10.3; $p<.001)$; in contrast, among subjects who denied functional drug use, amounts of khat use tended to be higher when no PTSD was found $(1.0 \pm 3.2,99 \%$ CI $0-2.9$ vs. $1.8 \pm 5.1,99 \%$ CI $1.5-$ $2.0 ; p=.017)$. When repeating this analysis for the North and the South of Somalia separately, the PTSD effect and the interaction effect were found only in the South.

Can PTSD and khat use explain psychotic symptoms? We hypothesized that PTSD is a risk factor for psychotic symptoms and that khat use is mediating this relationship. In order to graphically explore this relationship, we divided the whole group into subgroups according to PTSD and the amount of khat consumed in the past week: respondents without khat use, and four groups of khat users of sufficient size (Fig. 3). Groups were defined using the quartiles of the khat use distribution in the group of khat chewers with PTSD. The proportion of respondents with paranoid ideation increases in the subgroups with and without PTSD when khat use increases; only in the group with highest khat use ( $>24.5$ bundles per week), does the proportion of respondents with paranoid ideation decline.

In all subgroups, respondents with PTSD had a higher proportion of paranoid symptoms compared to respondents without PTSD.

The correlations between variables in our model are depicted in Table 3.

Table 2

Proportion of respondents with paranoid symptoms among ex-combatants with and without PTSD and with and without functional drug use. We report percentages, $99 \%$ CI (italic), and $N$ (in brackets).

\begin{tabular}{lllll}
\hline & & PTSD & \\
& & Without $(7667)$ & & With (456) \\
\hline Functional drug use & Without (6546) & $2.0 \%$ & & $15.7 \%$ \\
& & $1.56-2.43$ & & $5.9-24.1$ \\
& & $(128$ of 6444$)$ & & $(16$ of 102$)$ \\
& With (1577) & $12.2 \%$ & & $29.1 \%$ \\
& & $9.81-14.59$ & & $22.8-35.2$ \\
& & $(149$ of 1223$)$ & $(103$ of 354$)$ \\
\hline
\end{tabular}




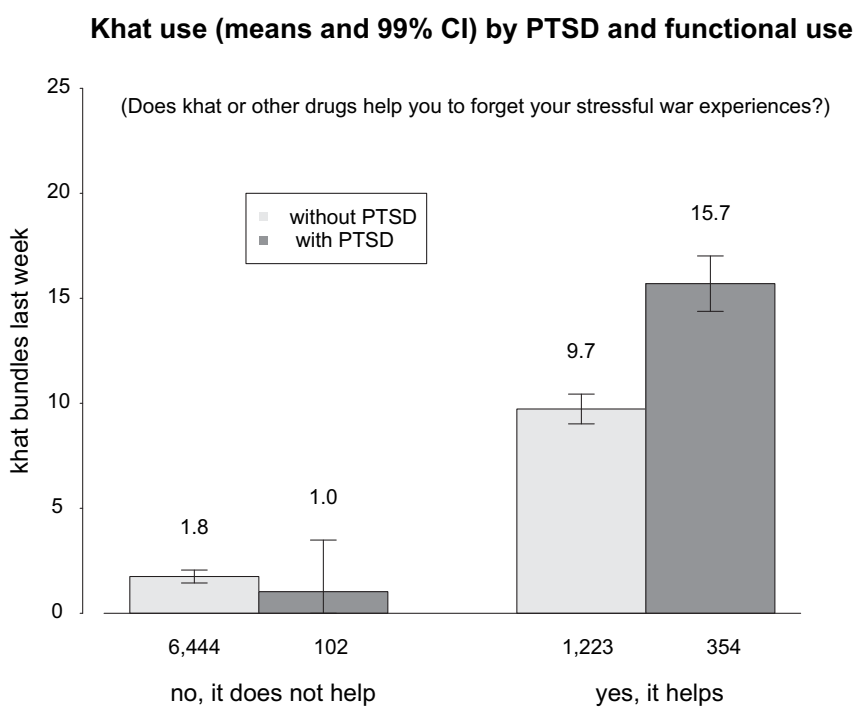

Fig. 2. Khat use in active personnel of armed groups in Somaliland. Comparison of khat use between groups of respondents with and without PTSD and with and without the subjective evaluation of khat and drugs as being helpful or not to forget warrelated memories. We report the average number of khat bundles consumed in the previous week and 99\% CIs. Below the bars, we report N.

In a set of three binary logistic regression models we tested a simple mediation model with khat use as mediating variable (Table 4). Age, gender and to a lesser extent, education are statistically significant covariates. Models 1-3 clearly show that there's no simple mediation effect (indirect effect) of khat quantity as indicated by a non-significant interaction term in model 3 . In models 4-6 (Table 4) we tested the more complex mediated moderation model in which the trait-like characteristic functional

\section{Proportions and $99 \% \mathrm{Cls}$ of respondents with paranoid symptoms} in groups of khat users with and without PTSD

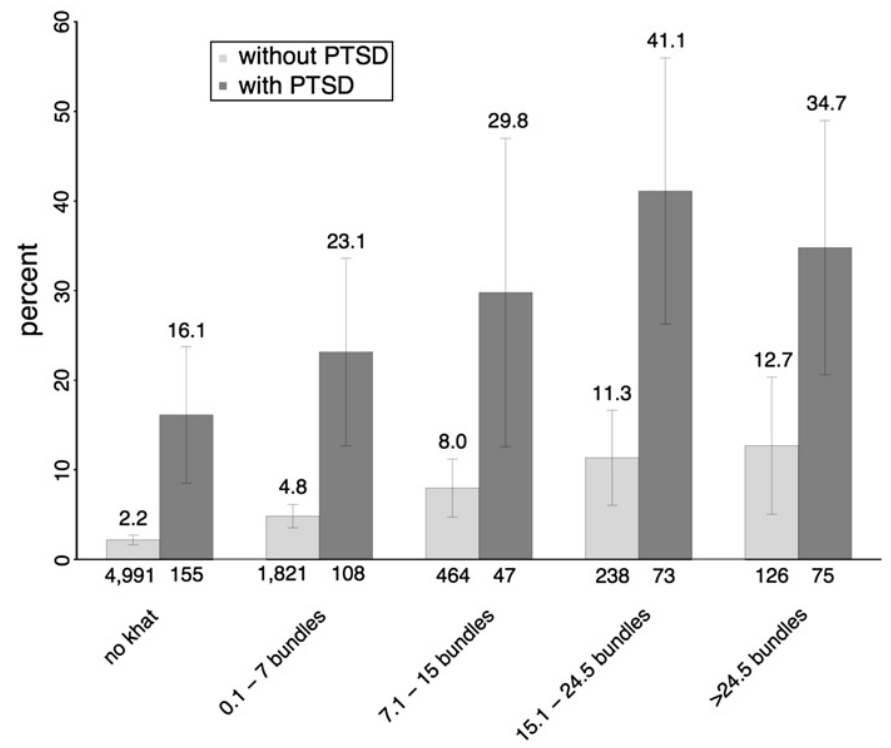

Fig. 3. Percentage of respondents with paranoid ideation. Groups were defined according to quantity of khat use in previous week and Posttraumatic Stress Disorder (PTSD). Groups of khat users were computed based on the quartiles of amount of khat use within the group with PTSD. Error bars correspond to 99\% CIs. Below the bars, we report $\mathrm{N}$.
Table 3

Correlation between variables in the binary regression model. We report $P h i$ and $N$ (in brackets).

\begin{tabular}{lllll}
\hline & PTSD & Functional drug use & Khat quantity & Paranoia \\
\hline PTSD & - & $0.359^{* *}(8123)$ & $0.222^{* *}(8124)$ & $0.240^{* *}(8124)$ \\
$\begin{array}{l}\text { Functional } \\
\quad\end{array}$ & - & $0.384^{* *}(8123)$ & $0.253^{* *}(8123)$ \\
Krug use & & & - & $0.172^{* *}(8124)$ \\
\hline Khat quantity & & & &
\end{tabular}

drug use was hypothesized to moderate the effect of PTSD on paranoia through the mediating mechanism of khat use quantity. Likelihood ratio tests were computed against the prior model. The significant interaction term in model 4 indicates the existence of the simple moderation effect. This model achieved a better overall fit than the simple model $1(p<.001)$. The interaction term in model 5 and the significant simple effect of khat quantity in model 6 indicate mediated moderation. The most complex model achieved a better fit than the simple moderation model $(p<.001)$.

The data-based model is depicted in Fig. 4.

When repeating logistic regression and ANOVA without women, the same results were achieved.

\section{Discussion}

We report on a large cross-sectional study with personnel of armed groups in Somalia, which uncovered the effects of khat use and PTSD on psychotic symptoms in ex-combatants. Our data support the hypothesis that PTSD and khat use have distinguishable effects on paranoia. This result contradicts the opinion among experts who argue that in studies with khat using migrants all psychopathology can be explained by exposure to stress (Pennings et al., 2008). Our data furthermore support the hypothesis that PTSD causes the use of higher quantities of khat. The increasing quantity of khat use appears to be one possible mechanism by which paranoia is caused, but especially among those individuals with PTSD, who functionally use it to cope with unpleasant emotions and symptoms. However, our data stem from a cross-sectional study and cannot be considered a proof of this specific causal chain that we proposed. Our data can be interpreted in the light of several possible causal chains, e.g. alternatively that paranoid individuals use khat in order to maintain themselves alert, as this is one of the traditional functions of khat use during religious ceremonies. However, based on the literature review above, we believe that the most plausible direction of causality is that paranoia is the outcome and PTSD and khat use increase its risk. Still, several hypothesis are possible within this causal chain, e.g. is it only because of their higher khat use that they are more likely to develop psychotic symptoms or because PTSD renders individuals more vulnerable for the psychotomimetic effects of khat? These different possible causal hypotheses should be tested against each other in future qualitative and quantitative studies, including experimental and longitudinal designs. The numeric values of all point estimates must be interpreted with caution because we only used screening instruments and the sampling methods that were used would not allow for estimation of biases.

Our findings are in line with a general 'dose-response effect' hypothesis, i.e. an increased risk for the development of paranoia exists in subjects with PTSD and further increases when more khat is consumed. Our findings are in accordance with the literature, as excessive khat use has previously been found to promote psychotic disorders (Odenwald, 2007; Warfa et al., 2007) and PTSD may have co-morbid psychotic features (Braakman et al., 2009). Furthermore, 


\section{Table 4}

Please note that in table 4, the line feed of the colums Predictor variables (left side of the table) is different than the same column at the right side. Please also note that the headings (Model $1-6$ ) the brackets start in the line or in the next line; better would be to let them start all in the next line. Test of simple mediation and mediated moderation. We report here six binary logistic regression models. Abbreviations: b, unstandardized binary regression coefficient. Wald, Wald statistic. DV, dependent variable.

\begin{tabular}{|c|c|c|c|c|c|c|c|c|c|c|c|c|c|}
\hline \multicolumn{7}{|c|}{ Testing simple mediation } & \multicolumn{7}{|c|}{ Testing mediated moderation } \\
\hline \multirow[t]{2}{*}{$\begin{array}{l}\text { Predictor } \\
\text { variables }\end{array}$} & \multicolumn{2}{|l|}{$\begin{array}{l}\text { Model } 1 \\
\text { (DV Paranoia) }\end{array}$} & \multicolumn{2}{|c|}{$\begin{array}{l}\text { Model } 2 \\
\text { (DV Khat quantity) }\end{array}$} & \multicolumn{2}{|c|}{$\begin{array}{l}\text { Model } 3 \\
\text { (DV: Paranoia) }\end{array}$} & \multirow[t]{2}{*}{$\begin{array}{l}\text { Predictor } \\
\text { variables }\end{array}$} & \multicolumn{2}{|c|}{$\begin{array}{l}\text { Model } 4 \\
\text { (DV: Paranoia) }\end{array}$} & \multicolumn{2}{|c|}{$\begin{array}{l}\text { Model } 5 \\
\text { (DV: Khat quantity) }\end{array}$} & \multicolumn{2}{|c|}{$\begin{array}{l}\text { Model } 6 \\
\text { (DV: Paranoia) }\end{array}$} \\
\hline & b & Wald & $\mathrm{b}$ & Wald & $\mathrm{b}$ & Wald & & $\mathrm{b}$ & Wald & b & Wald & $\mathrm{b}$ & Wald \\
\hline$\overline{\text { Age }}$ & -.024 & $20.157^{* *}$ & -.041 & $118.030^{* *}$ & -.019 & $11.874^{*}$ & Age & -.012 & $4.538^{*}$ & -.030 & $56.875^{* *}$ & -.010 & 2.920 \\
\hline Gender & 1.221 & $16.535^{* *}$ & 3.439 & $47.247^{* *}$ & 1.001 & $10.965^{*}$ & Gender & .708 & $5.337^{*}$ & 2.962 & $34.748^{* *}$ & .639 & $4.321^{*}$ \\
\hline Marital status & -.206 & 3.014 & -.188 & $5.601^{*}$ & -.164 & 1.881 & Marital status & -.140 & 1.387 & -.126 & 2.300 & -.136 & 1.281 \\
\hline $\begin{array}{l}\text { Primary } \\
\text { education }\end{array}$ & -.109 & .994 & .059 & .701 & -.113 & 1.061 & $\begin{array}{l}\text { Primary } \\
\text { education }\end{array}$ & -.009 & .007 & .191 & $6.531^{*}$ & -.022 & .040 \\
\hline PTSD & 2.032 & $258.883^{* *}$ & 1.582 & $224.058^{* *}$ & 1.905 & $116.553^{* *}$ & PTSD & 2.110 & $53.320^{* *}$ & -0.730 & 2.008 & 2.146 & $54.880^{* *}$ \\
\hline $\begin{array}{l}\text { Khat } \\
\text { quantity }\end{array}$ & & & & & 1.085 & $59.108^{* *}$ & $\begin{array}{r}\text { Functional } \\
\text { drug use }\end{array}$ & 1.762 & $181.485^{* *}$ & 1.734 & $450.249^{* *}$ & 1.625 & $119.752^{* *}$ \\
\hline \multirow[t]{3}{*}{$\begin{array}{c}\text { PTSD } \times \text { Khat } \\
\text { quantity }\end{array}$} & & & & & -.327 & 1.596 & $\begin{array}{l}\text { PTSD } \times \text { Functional } \\
\text { drug use }\end{array}$ & -1.031 & $10.104^{*}$ & 1.596 & $9.068^{*}$ & -1.167 & $12.788^{* *}$ \\
\hline & & & & & & & Khat quantity & & & & & .552 & $4.046^{*}$ \\
\hline & & & & & & & $\begin{array}{l}\text { Functional drug } \\
\text { use } \times \text { Khat } \\
\text { quantity }\end{array}$ & & & & & -.022 & .005 \\
\hline $\begin{array}{l}\text { Likelihood } \\
\text { ratio }(\mathrm{df})\end{array}$ & $2844.873(5)$ & & & & & & $\begin{array}{l}\text { Likelihood } \\
\text { ratio (df) }\end{array}$ & $\begin{array}{l}2,663,346 \\
(7)^{a}\end{array}$ & & & & & $\begin{array}{l}2646.309 \\
(9)^{\mathrm{b}}\end{array}$ \\
\hline
\end{tabular}

$p<.05,{ }^{* *} p<.001$

a Likelihood ratio test against Model $1, p<.001$

${ }^{b}$ Likelihood ratio test against Model $4, p<.001$

it is consistent with our previous work, which already had suggested the possibility of an association between khat use, trauma and psychosis (Odenwald et al., 2005).

In the literature it is well ackowledged that in the Somali culture the khat session per se is a source of social support to cope with

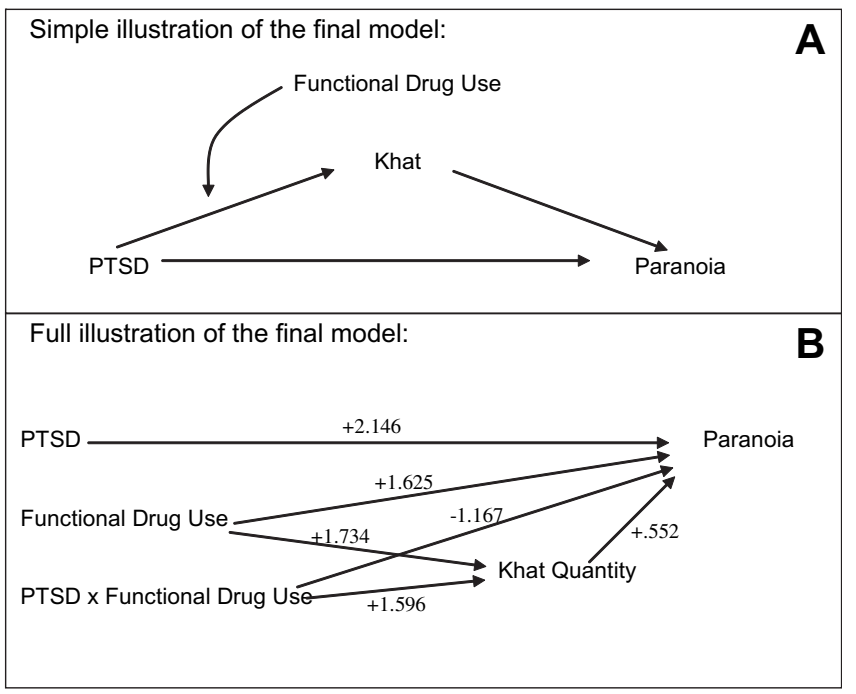

Fig. 4. Data-based model of mediated moderation: A) Simplified model (arrows of unsupported effects are omitted). B) Full description with logistic regression coefficients: The arrows represent significant effects from models $4-6$. The reported coefficients are unstandardized logistic regression coefficients. PTSD and functional drug use have direct effects on paranoia, i.e. respondents with PTSD and those, who report functional drug use, have a higher odds for paranoia. At the same time, functional drug use has an indirect effect via khat quantity, meaning that those who report functional drug use also report higher amount of khat use. The moderation effect of functional drug use is indicated by the direct effect of the interaction term on paranoia. The negative sign of the respective coefficient means that the odds ratio ( $\mathrm{p}_{\text {(para- }}$ noia =1) $(P T S D) / p_{(\text {paranoia=1) }}($ no PTSD)) is higher for those respondents who do not report functional drug use compared to those who do; but the absolute risk of those who report functional drug use is much higher. The mediated moderation becomes clear by the interaction effect on khat quantity and the simple effect of khat quantity on paranoia. experienced trauma. Here we describe that khat itself is used to cope with trauma. These data add another piece of evidence in favor of the hypothesis that traditional patterns of khat consumption have changed profoundly. Results indicate that khat use has a new function, i.e. to modify emotions related to experienced wartrauma and to cope with symptoms of PTSD. This result corresponds well to the literature on PTSD and stimulant use, which shows its functional use for depression (Brady et al., 1998). In this sense, khat use needs to be acknowledges as an important part of the local patterns of coping but also as an additional source of distress when it becomes compulsive and causes additional psychopathology. Our findings also point at inter-individual differences in khat's effects. We would presume that the difference between those respondents with PTSD who find khat helpful and those who don't might be related to the current psychiatric symptom characteristics. For instance, those with co-morbid depression might be more likely to experience positive effects (i.e. cheering-up) while those with chronic hyperarousal or with a tendency to react with psychotic features might find the effects unpleasant.

Our data revealed that there are clear gender differences. Men present more frequently with PTSD than women and were more likely to use khat and were more often paranoid. This result is in accordance with traditional practices, i.e. that khat is a predominantly male drug. However, it is likely that answers might be biased by the possibility that women are less likely to disclose khat use than men.

In northern Somalia the subgroup with PTSD and very high khat use is hardly represented in our sample. Among the regular armed forces in northern Somalia, persons with mental health problems would not be tolerated, are more likely to have been released from service and, thus, would not be part of the interviewed population. This explains the percentage "drop" in the last quartile in Fig. 3. In contrast, in southern Somalia there was active fighting, state failure and no social welfare system. In this situation, an armed group, which is usually defined by ethnic kinship, takes on the responsibility of caring for severely ill members.

Our data have high relevance for future DDR activities in the region. The international community needs to be prepared for 
a large number of ex-combatants suffering from drug abuse and complex psychiatric disorders that reduce their ability to reintegrate into civil society. Thus, special attention should be paid to the development of adequate psycho-social and medical support. In our eyes, there is substantial evidence to justify the allocation of scarce resources to mental health programs. We believe the international community needs to seriously invest in research activities that increase the knowledge on reintegration of ex-combatants.

The reported data also might contribute to the understanding of psychotic disorders in general: The behavioral sensitization paradigm is thought to provide insight into the neural substrate of both drug-induced and idiopathic psychosis (Kalivas \& Stewart, 1991); while developed in laboratory context, it has recently proved validity for the explanation of psychotic symptom relapse in humans (Yui et al., 2001). Based on these studies and our findings, we speculate that the latent vulnerability for the development of psychotic disorders might not just be triggered but even acquired by early onset or excessive khat use in combination with the exposure to traumatic stress and or the development of PTSD.

Some critical points might be raised concerning the methods we used. The present sample might not have been representative and our assessment method might have led to an underestimation of the prevalence of PTSD and khat use. However, the uncovering of relations does neither require a representative sample nor accurate point estimates. The observation of a systematic effect despite the present shortcoming indicates a high power of the detected effects. Moreover, our study could be criticized because in developing countries, paranoia might not be related to disorders of the schizophrenia spectrum but rather be an unspecific symptom (Manton, Korten, Woodbury, Anker, \& Jablensky, 1994). Against this view we argue that in another sample (Odenwald, Lingenfelder, et al., 2007) we assessed a broad range of positive psychotic symptoms and found similar results. Paranoid symptoms are relevant signs of vulnerability for psychotic disorders, as shown in studies of the continuum model of psychosis and psychosis proneness (van Os, Verdoux, Bijl, \& Ravelli, 1999). Another point of criticism might be the quantitative assessment of khat consumption. Numerous qualities of khat with different contents of psychoactive agents are known (Al-Motarreb, Baker, \& Broadley, 2002). But there is reason to believe that there is a positive relationship between the consumption of traded units and consequences (Odenwald, Hinkel, et al., 2007). We argue, as have other researchers (Dhadphale \& Omolo, 1988; Kassim \& Croucher, 2006; Mion \& Oberti, 1998; Patel, Wright, \& Gammampila, 2005), that the assessment of traded units is a viable compromise in the absence of other quantitative methods applicable under present field conditions. Our assessment methods can be criticized because we relied on a small number of items and because the PTSD screener had a limited sensitivity. However, in previous studies, we had demonstrated the reliability and validity of our screening method for PTSD (Odenwald, Lingenfelder, et al., 2007) and the single-item assessment of psychiatric symptoms with the clinical interview method is frequently used in psychiatric research. Furthermore, the CIDI was developed and validated to be used by trained lay interviewers. Finally, another criticism might be that the subjects' report of drug use as a means to ameliorate PTSD symptoms might, in fact, be khat addiction since it is well known that withdrawal symptoms can reactivate PTSD symptoms (Jacobsen et al., 2001). If this is true, the reactivation of PTSD symptoms can be understood as an endpoint of a development, in which functional drug use possibly plays a role in the initiation and dependency contributes to maintaining drug use. Thus, when PTSD symptoms are reactivated in states of withdrawal, and, thus khat is consumed, this is still functional use. It is part of a complex psychiatric condition in which the distinction between single disorders is somehow artificial although they all need to be taken into account, particularly when it comes to treatment.

Khat is a substance with an astonishing complexity - its indisputable cultural value and traditional social use, its link to Muslim traditions, the specific history of regulation attempts, its recent economic boom in countries plagued by underdevelopment and conflict, providing livelihood to millions of people, its link to global markets and migration movements, the newly emerging patterns of excessive use, its marked health consequences, and last but not least its capacity to divide the public in many countries, as well as the heated academic controversy around it. This leads to a situation in which a comprehensive and balanced view is hard to reach, harder than in the case of other substances. We believe that gaining a deeper understanding of the multi-faceted aspects of khat through social science and biomedical research is the only way to cut this Gordian knot.

When it comes to intervention, the problems associated to khat cannot be simply solved by a ban, as attempted in the past (Warfa et al., 2007). Rather, balanced and evidence-based action should be favored, including raising awareness about inherent health dangers, the development of harm reduction and regulation mechanisms, and the development of alternative ways of income generation.

\section{Acknowledgements}

We express our thanks to the following persons from the University of Konstanz: Dr. Willi Nagl, who assisted with the data analysis, Dr. Sandra Janzen, who provided useful comments on the draft of this manuscript, and Dr. Nathan Weisz, who gave advice on the production of graphics. We also thank Dr. Christina O'Flaherty, who reviewed the language of the manuscript.

This research was financed by the European Commission and implemented on the ground by German Technical Cooperation (GTZ). Neither organization had influence on analysis and interpretation of the data, on the writing of this manuscript, nor on the decision to publish. The content of this article does not necessarily reflect the opinion of these organizations.

\section{References}

Advisory Council on the Misuse of Drugs. (2005). Khat (Qat): assessment of risk to individual and communities in the UK. In Advisory Council on the Misuse of Drugs (ACMD). London: British Home Office.

Al-Motarreb, A., Baker, K., \& Broadley, K. J. (2002). Khat: pharmacological and medical aspects and its social use in Yemen. Phytotherapy Research, 16(5), 403-413.

Anderson, D., Beckerleg, S., Hailu, D., \& Klein, A. (2007). The Khat controversy: Stimulating the debate on drugs. Oxford: Berg.

Angrist, B., Rotrosen, J., \& Gershon, S. (1980). Differential effects of amphetamine and neuroleptics on negative vs. positive symptoms in schizophrenia. Psychopharmacology (Berl), 72(1), 17-19.

Baicy, K., \& London, E. D. (2007). Corticolimbic dysregulation and chronic methamphetamine abuse. Addiction, 102(Suppl. 1), 5-15.

Baron, R. M., \& Kenny, D. A. (1986). The moderator-mediator variable distinction in social psychological research: conceptual, strategic, and statistical considerations. Journal of Personality and Social Psychology, 51(6), 1173-1182.

Bell, D. S. (1973). The experimental reproduction of amphetamine psychosis. Archives of General Psychiatry, 29(1), 35-40.

Bhui, K., Abdi, A., Abdi, M., Pereira, S., Dualeh, M., Robertson, D., et al. (2003). Traumatic events, migration characteristics and psychiatric symptoms among Somali refugees-preliminary communication. Social Psychiatry and Psychiatric Epidemiology, 38(1), 35-43.

Bhui, K., Craig, T., Mohamud, S., Warfa, N., Stansfeld, S. A., Thornicroft, G., et al. (2006). Mental disorders among Somali refugees developing culturally appropriate measures and assessing socio-cultural risk factors. Social Psychiatry and Psychiatric Epidemiology, 41, 400-408.

Bimerew, M. S., Sonn, F. C. T., \& Korlenbout, W. P. (2007). Substance abuse and the risk of readmission of people with schizophrenia at Ammanual Psychiatric Hospital, Ethiopia. Curationis, 30(2), 74-81. 
Boys, A., \& Marsden, J. (2003). Perceived functions predict intensity of use and problems in young polysubstance users. Addiction, 98(7), 951-963.

Braakman, M. H., Kortmann, F. A., \& van den Brink, W. (2009). Validity of 'posttraumatic stress disorder with secondary psychotic features': a review of the evidence. Acta Psychiatrica Scandinavica. Supplementum, 119(1), 15-24.

Brady, K. T., Dansky, B. S., Sonne, S. C., \& Saladin, M. E. (1998). Posttraumatic stress disorder and cocaine dependence. Order of onset. American Journal on Addictions, 7(2), 128-135.

Coffey, S. F., Saladin, M. E., Drobes, D. J., Brady, K. T., Dansky, B. S., \& Kilpatrick, D. G. (2002). Trauma and substance cue reactivity in individuals with comorbid posttraumatic stress disorder and cocaine or alcohol dependence. Drug and Alcohol Dependence, 65(2), 115-127.

Coffey, S. F., Schumacher, J. A., Brady, K. T., \& Cotton, B. D. (2007). Changes in PTSD symptomatology during acute and protracted alcohol and cocaine abstinence. Drug and Alcohol Dependence, 87(2-3), 241-248.

Daly, O. E. (2000). The use of stimulants in the treatment of post traumatic stress disorder: case report. Human Psychopharmacology, 15(4), 295-300.

Dhadphale, M., \& Omolo, O. E. (1988). Psychiatric morbidity among khat chewers. East African Medical Journal, 65(6), 355-359.

Fangen, K. (2006). Humiliation experienced by Somali refugees in Norway. Journal of Refugee Studies, 19(1), 69-93.

Foa, E. B., Cashman, L., Jaycox, L., \& Perry, K. (1997). The validation of a self-report measure of posttraumatic stress disorder: the posttraumatic diagnostic scale. Psychological Assessment, 9(4), 445-451.

Hinkel, H. (2004). Discussion paper for ceasefire, security sector rebuilding, disarmament, demobilization and reintegration planning for Somalia. Nairobi: German Technical Cooperation (GTZ)

Jacobsen, L. K., Southwick, S. M., \& Kosten, T. R. (2001). Substance use disorders in patients with posttraumatic stress disorder: a review of the literature. American Journal of Psychiatry, 158(8), 1184-1190.

Kalivas, P. W., \& Stewart, J. (1991). Dopamine transmission in the initiation and expression of drug- and stress-induced sensitization of motor activity. Brain Research. Brain Research Review, 16(3), 223-244.

Kalix, P. (1996). Catha edulis, a plant that has amphetamine effects. Pharmacy World E' Science, 18(2), 69-73.

Kassim, S., \& Croucher, R. (2006). Khat chewing amongst UK resident male Yemeni adults: an explanatory study. International Dental Journal, 56, 97-101.

Kienzler, H. (2008). Debating war-trauma and post-traumatic stress disorder (PTSD) in an interdisciplinary arena. Social Science E Medicine, 67(2), 218-227.

Krikorian, A. D. (1983). Khat and its use: an historical perspective. In B. Shanahdeh, R Geadah, A. Tongue, E. Tongue, J. Rolli(Eds.) International conference on Khat: The health and socio-economic aspects of Khat use. Antananaribo, Madagaskar: International Council Against Alcohol and Addictions, ICAA, Lausanne, Switzerland.

Kulka, R. A., Schlenger, W. E., Fairbank, J. A., Hough, R. L., Jordan, B. K. Marmar, C. R., et al. (1990). Trauma and the Vietnam War generation: Report of findings from the National Vietnam Veterans Readjustment Study. New York: Brunner/Mazel.

MacKinnon, D. P., \& Dwyer, J. H. (1993). Estimating mediated effects in prevention studies. Evaluation Review, 17(2), 144-158.

Manton, K. G., Korten, A., Woodbury, M. A., Anker, M., \& Jablensky, A. (1994). Symptom profiles of psychiatric disorders based on graded disease classes: an illustration using data from the WHO International Pilot Study of Schizophrenia. Psychological Medicine, 24(1), 133-144.

Mion, G., \& Oberti, M. (1998). Epidemiologic study of qat use in the National Army of Djibouti. Médecine Tropicale, 58(2), 161-164.

Mogapi, N. (2004). Reintegration of soldiers: the missing piece. Intervention, 2(3), 221-225.
Muller, D., Judd, C. M., \& Yzerbyt, V. Y. (2005). When moderation is mediated and mediation is moderated. Journal of Personality and Social Psychology, 89(6) 852-863.

Nabuzoka, D., \& Badhadhe, F. A. (2000). Use and perception of khat among young Somalis in a UK city. Addiction Research, 8(1), 5-26.

Ndetei, D. M. (1988). Psychiatric phenomenology across countries: constitutional, cultural, or environmental? Acta Psychiatrica Scandinavica. Supplementum, 344, $33-44$.

Odenwald, M. (2007). Chronic khat use and psychotic disorders: a review of the literature and future prospects. Sucht, 53(1), 9-22.

Odenwald, M., Hinkel, H., Schauer, E., Neuner, F., Schauer, M., Elbert, T., et al. (2007). The consumption of khat and other drugs in Somali combatants: a crosssectional study. PLoS Medicine, 4(12), e341.

Odenwald, M., Lingenfelder, B., Schauer, M., Neuner, F., Rockstroh, B., Hinkel, H., et al. (2007). Screening for posttraumatic stress disorder among Somali excombatants: a validation study. Conflict and Health, 1(10). doi:10.1186/ 1752-1505-1181-1110.

Odenwald, M., Neuner, F., Schauer, M., Elbert, T. R., Catani, C., Lingenfelder, B., et al. (2005). Khat use as risk factor for psychotic disorders: a cross-sectional and case-control study in Somalia. BMC Medicine, 3(1), 5.

van Os, J., Verdoux, H., Bijl, R., \& Ravelli, A. (1999). Psychosis as an extreme of continuous variation in dimensions of psychopathology. In W. F. Gattaz, \& H. Häfner (Eds.), Balance of the century. Search for the causes of schizophrenia, Vol. IV. Darmstadt: Steinkopff.

Patel, S. L., Wright, S., \& Gammampila, A. (2005). Khat use among Somalis in four English cities. Home Office.

Pennings, E. J. M., Opperhuizen, A., \& van Amsterdam, J. G. C. (2008). Risk assessment of khat use in the Netherlands. A review based on adverse health effects, prevalence, criminal involvement and public order. Regulatory Toxicology and Pharmacology. online pre-publication.

Rousseau, C., Said, T. M., Gagne, M. J., \& Bibeau, G. (1998). Between myth and madness: the premigration dream of leaving among young Somali refugees. Culture, Medicine and Psychiatry, 22(4), 385-411.

Savoca, E., \& Rosenheck, R. (2000). The civilian labor market experiences of Vietnam-era veterans: the influence of psychiatric disorders. Journal of Mental Health Policy and Economics, 3(4), 199-207.

Seedat, S., Stein, M. B., Oosthuizen, P. P., Emsley, R. A., \& Stein, D. J. (2003). Linking posttraumatic stress disorder and psychosis: a look at epidemiology, phenomenology, and treatment. The Journal of Nervous and Mental Disease, 191(10), 675-681.

Smith, C. (2002). Evaluation of the Somalia North West demobiolization and reintegration programme. Aylesbury, UK: Agrisystems Limited.

Szendrei, K. (1980). The chemistry of khat. Bulletin on Narcotics, 32(3), 5-35.

Warfa, N., Klein, A., Bhui, K., Leavey, G., Craig, T., \& Stansfeld, S. A. (2007). Khat use and mental illness: a critical review. Social Science E Medicine, 65, 309-318.

WHO. (2008). Rapid assessment of alcohol and other substance use in conflictaffected and displaced populations: A field guide. Geneva: World Health Organization. p. 52.

World Health Organization. (1997). Composite International Diagnostic Interview (CIDI): Core version 2.1. Geneva: World Health Organization.

Yui, K., Goto, K., Ikemoto, S., Nishijima, K., Yoshino, T., \& Ishiguro, T. (2001) Susceptibility to subsequent episodes of spontaneous recurrence of methamphetamine psychosis. Drug Alcohol Dependence, 64(2), 133-142.

Zarowsky, C. (2000). Trauma stories: violence, emotion and politics in Somali Ethiopia. Transcultural Psychiatry, 37(3), 383-402.

Zarowsky, C., \& Pedersen, D. (2000). Rethinking trauma in a transnational world. Transcultural Psychiatry, 37(3), 291-293. 